\title{
UCLA
}

Mester

Title

Blanco y negro

Permalink

https://escholarship.org/uc/item/2g16s7fm

Journal

Mester, 3(2)

Author

Castañeda, Julio R.

Publication Date

1973

DOI

10.5070/M332013453

Copyright Information

Copyright 1973 by the author(s). All rights reserved unless otherwise indicated. Contact the author(s) for any necessary permissions. Learn more at https://escholarship.org/terms

Peer reviewed 
encuentra en un estadio más avanzado en el análisis de su impacto e influencia en la socicdad francesa durante y después de la segunda guerra mundial. Que los franceses han llegado ya a algunas conclusiones definitivas - no demasiado halagueñas, por cier to- lo prueba el reciente e impresionante documental de Ophul i.a douleur et la pitié.

${ }^{6} J u a n$ Goytisolo, El Furgón de cola. (Paris: Ruedo lbérico, 1967), p. 43 (La cursiva es mía).

${ }^{7}$ Georg Lukacs, The Meaning of Contemporary Realism, (London: Merlin Press, 1962). Ver sobre todo el ensayo The Ideology' of Modernism.

${ }^{8}$ Lukacs, Ihid., pp. 47 y ss.

\section{Blanco y negro}

El blanco no es tan blanco como la garza rápida que va hacia la montaña como flecha certera.

¿Qué es ser criatura blanca?

El negro no es tan negro como el carbón que entrega el diamante de fuego que adorna una garganta. ¿Qué es ser criatura negra?

Si el blanco no es tan blanco $y$ el negro no es tan negro, ¿no es posible hallar algo que llamemos hermano que borre en el espejo de nuestras convicciones la gama inconsecuente que hace lo negro odio y el odio blanco imperio?

El odio sí es lo blanco. El odio sí es lo negro.

Julio R. Castañeda 